Michael P. Craven, Maria Laura De Filippis and Tom Dening. Quality of Life Tools to Inform Co-design in the Development of Assistive Technologies for People with Dementia and their Carers, in Leandro Pecchia, Liming Luke Chen, Chris Nugent, José Bravo (Eds.). Ambient Assisted Living and Daily Activities, Lecture Notes in Computer Science Volume 8868, 2014, pp. 394-397 (6th International WorkConference, IWAAL 2014, Belfast, UK, December 2-5, 2014. Proceedings). doi: 10.1007/978-3-319-13105-4 57

\title{
Quality of Life Tools to Inform Co-design in the Development of Assistive Technologies for People with Dementia and their Carers
}

\author{
Michael P. Craven ${ }^{1,3}$, Maria Laura De Filippis ${ }^{2,3}$, Tom Dening ${ }^{2,3}$ \\ ${ }^{1}$ The University of Nottingham, Electrical Systems \& Optics Research Division, Faculty of \\ Engineering, University Park, Nottingham NG7 2RD, United Kingdom. \\ ${ }^{2}$ The University of Nottingham, Division of Psychiatry and Applied Psychology, The Institute \\ of Mental Health, Jubilee Campus, Nottingham, NG7 2TU, United Kingdom. \\ ${ }^{3}$ NIHR MindTech Healthcare Technology Co-operative, The Institute of Mental Health, Jubilee \\ Campus, Nottingham, NG7 2TU, United Kingdom. \\ \{michael.craven, maria.de filippis, tom.dening\}@nottingham.ac.uk
}

\begin{abstract}
A number of tools exist to measure quality of life (QoL) for people with dementia $(\mathrm{PwD})$. A selection of existing measures are summarised, obtained from an online literature survey, comprising of scales administered either by healthcare professionals with the PwD (self-report) and/or their carers (proxy report) or from observation. It is suggested that a combination of such tools with user satisfaction questionnaires may provide a way to approach the problem of evaluating Assistive Technology (AT) solutions or inform co-design of technological solutions with PwD and their carers.
\end{abstract}

Keywords: Assistive Technologies, Telecare, Ambient Assisted Living, User experience, Dementia, Quality of Life measures, Health Technology Assessment

\section{Introduction}

A major goal of designers during preliminary phases of development of new technology products is to investigate user expectations, needs and desires, in recognition of the distance between mental model(s) of designers and those of users. In particular this distance needs to be reduced when the designed product is an Assistive Technologies (AT) for people with dementia (PwD), in order prevent nonuse or abandonment [1]. In the field of interaction design there is a long tradition of user involvement in early design stages which and such methods are being applied to technology support for PwD and carers [2]. One approach to eliciting user needs is to investigate dimensions of quality-of-life (QoL)[3],[4], [5].

As Peterson et al. have noted [6], tools in use are mainly derived from the constructs of Lawton. There are two main ways to determine QoL of patients with dementia: i) Questionnaires and interviews (self-report by the PwD and/or proxyreport by the carer) and ii) direct observation of behaviours assumed to be related to QoL. The selection of the most appropriate tool will depend on the setting (home or 
care institution), the severity of dementia and the nature of the technology being considered. The advantage of using disease specific tools in pre-design and post-use phases are: i) to understand which are the needs and aspirations of PwD on the basis of reported or observable aspects of their daily life, ii) an indirect measure of the potential impact of ATs in their life, based on the improvement in their QoL that the technology could provide.

\section{Quality of Life (QoL) tools}

In the following section, in Table 1, a summary of tools to measure QoL for PwD are presented. The search was performed on Google Scholar with free text search terms: \{dementia\}AND \{quality-of-life, QoL, scales\} for English language papers (including reviews) published in the last 20 years. The tools selected were those intended to be administered by healthcare professionals with the PwD (self-report) and/or their carers (proxy report) or from observation. Papers solely about staging were excluded.

Table 1. QoL tools for people with dementia

\begin{tabular}{|c|c|}
\hline Name & Description \\
\hline $\begin{array}{l}\text { Cornell-Brown } \\
\text { Scale for Quality of } \\
\text { Life in Dementia } \\
(\mathrm{CBS})[7]\end{array}$ & $\begin{array}{l}\text { Clinician rated scale administered jointly with the PwD and carer using } 19 \text { bipolar } \\
\text { items }(-2,+2) \text { in a semi-structured interview format, to provide a single score (- } \\
38,+38) \text {. High QoL is indicated by the presence of positive affect, physical and } \\
\text { psychological satisfactions, self-esteem and the relative absence of negative affect } \\
\text { and experience. Adapted from the Cornell Scale for Depression in Dementia. Can } \\
\text { be used for mild, moderate and severe dementia although for severe the validity and } \\
\text { reliability may be affected by lack of patient self-observations. }\end{array}$ \\
\hline $\begin{array}{l}\text { Dementia Quality } \\
\text { of Life Instrument } \\
\text { (DQoL)[8] }\end{array}$ & $\begin{array}{l}\text { Administered to PwD with mild to moderate dementia. 5-point visual scale used to } \\
\text { present multiple choice questions. Each point on the scale is associated with a } \\
\text { verbal description. } 29 \text {-item scale to measures } 5 \text { domains of QoL: Positive Affect ( } 6 \\
\text { items), Negative Affect ( } 11 \text { items), Feelings of Belonging ( } 3 \text { items), Self-esteem ( } 4 \\
\text { items), and Sense of Aesthetics ( } 5 \text { items) plus one global item (Overall, how would } \\
\text { rate your quality of life?). Subscale scores are not summed. }\end{array}$ \\
\hline $\begin{array}{l}\text { Quality of Life- } \\
\text { Alzheimer's Disease } \\
\text { (QoL-AD)[9] }\end{array}$ & $\begin{array}{l}\text { Questionnaire of } 13 \text { items designed to provide seperate PwD and carer reports of } \\
\text { the patient's QoL with a } 4 \text { point rating }(1=\text { poor, } 4=\text { excellent). Measures domains } \\
\text { of physical condition, mood, memory, functional abilities, interpersonal } \\
\text { relationships, ability to participate in meaningful activities, financial situation, and } \\
\text { global assessments of self-as-a-whole and QoL-as-a-whole. Response options are 4- } \\
\text { point multiple choice options ( } 1=\text { poor, } 4=\text { excellent). Overall score range }(13,52) \text {. } \\
\text { Composite scores that combine reports from patients and caregivers are weighted to } \\
\text { favour patient self-reporting. Can be used for mild, moderate and severe dementia }\end{array}$ \\
\hline $\begin{array}{l}\text { Quality of Life } \\
\text { Assessment } \\
\text { Schedule } \\
\text { (QOLAS)[10] }\end{array}$ & $\begin{array}{l}\text { Interview and rating scale where PwD and carers (may include care home staff) are } \\
\text { interviewed separately to identify } 2 \text { QoL issues for each of } 5 \text { domains: Physical, } \\
\text { Psychological, Social/family, Usual activities, and Cognitive functioning. PwD and } \\
\text { carers rate each issue they have identified 6-point scale }(0=\text { no problem, } 5=\text { it } \\
\text { could not be worse). Overall score range }(0,50) \text { with higher score for poorer QoL. }\end{array}$ \\
\hline DEMQOL[11] & $\begin{array}{l}\text { Health professional administered questionnaires to assess health related quality of } \\
\text { life for PwD and/or carer as proxy. There are two versions: } 28 \text {-item DEMQOL for } \\
\text { people with mild/moderate dementia and } 31 \text { item DEMQOL-proxy for carers of } \\
\text { people with mild/moderate dementia or with severe dementia. } 4 \text { point scale. }\end{array}$ \\
\hline
\end{tabular}




\begin{tabular}{|l|l|}
\hline OPQOL-35[12] & $\begin{array}{l}\text { 35-item questionnaire. Not a dementia-specific tool but can be applicable to people } \\
\text { with mild to moderate dementia. 5 point scale. }\end{array}$ \\
\hline $\begin{array}{l}\text { Alzheimer Disease } \\
\text { Related Quality of } \\
\text { Life (ADRQL)[13] }\end{array}$ & $\begin{array}{l}\text { Binary (Agree, Disagree) questions administered to the carer as proxy to the PwD } \\
\text { in a structured interview format. The ADRQL evaluates 5 QoL domains: social } \\
\text { interaction, awareness of self, feelings and mood, enjoyment of activities, response } \\
\text { to surroundings. There are two versions of ADRQL, the original composed of } 47 \\
\text { items and a revised version with 40 items, the majority of items in both versions } \\
\text { measuring actions and observable behaviours. Each item has a specific numerical } \\
\text { score provided in the ADRQL manual. }\end{array}$ \\
\hline $\begin{array}{l}\text { Quality of Life in } \\
\text { Late-Stage } \\
\text { (QUAmentia }\end{array}$ & $\begin{array}{l}\text { Carer (proxy report) instrument that measures 11 observable behaviours of PwD } \\
\text { over 7 days, indicating activity and emotional states, administered by nursing home } \\
\text { personnel. 5-point Likert scale. Designed for quick administration (5 minutes). }\end{array}$ \\
\hline $\begin{array}{l}\text { Dementia Care } \\
\text { Mapping } \\
\text { (DMC)[15] }\end{array}$ & $\begin{array}{l}\text { Structured observational tool for assessing PwD well-being in residential care who } \\
\text { are unable to provide their own report. Health professional administered. Covers all } \\
\text { stages of dementia (mild, middle or severe). Well-being and activities are recorded } \\
\text { every 5 minutes over a period of 6 hours. 24 activity categories and indicators of } \\
\text { social withdrawal are measured in terms of ill-being/well-being (-5, +5). }\end{array}$ \\
\hline
\end{tabular}

\section{Conclusions}

Although a number of valid and consistent QoL scales are in use there is presently no one tool to directly assess the impact of AT for dementia in terms of QoL improvement [6]. Consequently there is a lack of a standard approach to formative evaluation and user-centred design of new AT for PwD and their carers. However, some tools exist to evaluate user satisfaction and usability after a use of an AT prototype e.g., Psychosocial Impact of Assistive Devices Scale (PIADS)[16], Quebec User Evaluation of Satisfaction with Assistive Technology (QUEST)[17] which may be used in formative evaluation. For people with mild or moderate dementia a combination of QoL tools with satisfaction questionnaires may provide a solution which therefore warrants further investigation e.g. to determine which tools to combine. There is unmet need of a tool for severe dementia related to AT evaluation with respect to QoL, although the proxy version of PIADS may be applicable.

\section{Acknowledgements}

The research reported in this paper was conducted by the National Institute for Health Research MindTech Healthcare Technology Co-operative (NIHR MindTech HTC). The views expressed are those of the author(s) and not necessarily those of the NHS, the NIHR or the Department of Health. The authors acknowledge funding support for the research through the Connecting Assistive Solutions to Aspirations (CASA) project, provided by the Technology Strategy Board Long Term Care Revolution initiative by means of a Small Business Research Initiative grant. The CASA project is a collaborative venture led by commercial partner Leone Services Ltd., in 
partnership with Sensixa Ltd., The University of Nottingham, University of the West of England, Bristol and Swiss Cottage School, Development \& Research Centre.

\section{References}

1. Scherer, M. J. Outcomes of assistive technology use on quality of life. Disability \& Rehabilitation, 18(9): pp. 439-448 (1996)

2. Lindsay, S., et al. Empathy, participatory design and people with dementia. in Proceedings of the SIGCHI Conference on Human Factors in Computing Systems, ACM Press, pp. 521-530 (2012).

3. Ettema, T. P., et al. A review of quality of life instruments used in dementia. Quality of Life Research, 14(3), pp. 675-686 (2005).

4. Ready, R. E. and Ott, B. R. Quality of life measures for dementia. Health and Quality of Life Outcomes, 1(11): p. 1-9 (2003)

5. Orpwood, R., et al., Designing technology to support quality of life of people with dementia. Technology and Disability, 19(2), pp. 103-112 (2007).

6. Peterson, C. B., Prasad, N. R. and Prasad, R. Assessing assistive technology outcomes with dementia. Gerontechnology, 11(2), pp. 259-268 (2012).

7. Ready, R. E., et al. The Cornell-Brown scale for quality of life in dementia. Alzheimer Disease \& Associated Disorders, 16(2): p. 109-115 (2002)

8. Brod, M., et al. Conceptualization and measurement of quality of life in dementia: The dementia quality of life instrument (DQoL). The Gerontologist, 39(1), pp. 25-36 (1999).

9. Hoe, J., et al. Use of the QOL-AD for measuring quality of life in people with severe dementia - the LASER-AD study. Age and ageing, 34(2), pp. 130-135 (2005).

10. Selai, C.E., et al. Assessing quality of life in dementia: Preliminary psychometric testing of the Quality of Life Assessment Schedule (QOLAS). Neuropsychological Rehabilitation, 11(3-4), pp. 219-243 (2001).

11. Smith, S., et al. Measurement of health-related quality of life for people with dementia: development of a new instrument (DEMQOL) and an evaluation of current methodology. Health Technology Assessment, 9(10), pp. 1-93 (2005)

12. Bilotta, C., et al. Quality of life in older outpatients living alone in the community in Italy. Health \& social care in the community, 20(1), pp. 32-41 (2012).

13. Rabins, P.V., et al. Concepts and methods in the development of the ADRQL: An instrument for assessing health-related quality of life in persons with Alzheimer's disease. Journal of Mental Health and Aging, 5(1), pp. 33-48 (1999).

14. Weiner, M.F., et al. The quality of life in late-stage dementia (QUALID) scale. Journal of the American Medical Directors Association, 1(3), pp. 114-116 (1999).

15. Fossey, J., Lee, L., Ballard, C. Dementia Care Mapping as a research tool for measuring quality of life in care settings: Psychometric properties. International Journal of Geriatric Psychiatry, 17(11), pp. 1064-1070 (2002).

16. Jutai, J., Day, H. Psychosocial impact of assistive devices scale (PIADS). Technology and Disability, 14(3), p. 107-111 (2002).

17. Demers, L., Weiss-Lambrou, R., Ska, B. The Quebec User Evaluation of Satisfaction with Assistive Technology (QUEST 2.0): an overview and recent progress. Technology and Disability, 14(3), pp. 101-105 (2002). 